\title{
Induction of Tolerance to Non Steroidal Anti Inflammatory Drugs Might Be an Alternative Therapeutic in the Painful Crisis of Sickle Cell Disease
}

\author{
Dasse Romuald1*, Kouacou Amah'1, Akré Paul2, Yeboah Richard1, Nguessan Koffi1, \\ Sombo François ${ }^{1}$ \\ ${ }^{1}$ Department of Immunology, Hematology and Allergology of CHU de Cocody BP V 13, Abidjan, Côte d'Ivoire \\ ${ }^{2}$ Department of Immunology of CHU de Bouake, Bouake, Côte d'Ivoire \\ Email: $\underline{\text { serydasse@yahoo.fr }}$
}

Received 14 October 2013; revised 14 November 2013; accepted 21 November 2013

Copyright (C) 2014 by authors and Scientific Research Publishing Inc.

This work is licensed under the Creative Commons Attribution International License (CC BY).

http://creativecommons.org/licenses/by/4.0/

(c) (i) Open Access

\section{Abstract}

Background and Aims: In Ivoirian's school, the management of vaso-occlusive painful crisis in sickle cell disease requires non steroidal anti inflammatory drugs (NSAIDs). Although their effectiveness, these drugs may be accompanied by intolerance reactions. When these occur, no codified alternative therapeutic seems to be used to our knowledge. Authors aimed to evaluate the induction of tolerance to NSAIDs as an effective alternative therapeutic. Methods: 22 patients (15 men and 7 women aged from 12 to 39 years with mean age: $22.41 \pm 7.88$ ) suffering from vaso-occlusive painful crisis were enrolled. They were known to have a history of sickle cell disease and at least one episode of adverse reactions following the Ibuprofen or Diclofenac intake. A rapid protocol of oral challenge was used in patients to induce tolerance to NSAIDs. The first day, initial doses (8.82 $\mathrm{mg}$ for Ibuprofen and $2.20 \mathrm{mg}$ for Diclofenac) were given and gradually increased at intervals of 1 hour over a total period of 6 hours. On the second and third days, the therapeutic dose has been orally administrated with an interval of 6 hours over a period of 12 hours. Results: Despite of some cases of failure that might be related to the severity of symptoms or possible patho-physiological mechanism, more than $80 \%$ of patients have successfully tolerated Diclofenac and Ibuprofen. Conclusion: This experience appears to be the first in our context. It might be used as a solution in the lack of alternative therapeutic in the management of vaso-occlusive painful crisis of sickle cell disease as well as in other diseases such as HIV infection where patients often develop intolerance to none alternative antibiotics.

*Corresponding author.

How to cite this paper: Romuald, D., Amah, K., Paul, A., Richard, Y., Koffi, N. and François, S. (2014) Induction of Tolerance to Non Steroidal Anti Inflammatory Drugs Might Be an Alternative Therapeutic in the Painful Crisis of Sickle Cell Disease. Journal of Immune Based Therapies, Vaccines and Antimicrobials, 3, 11-21. http://dx.doi.org/10.4236/jibtva.2014.32002 


\section{Keywords}

\section{Induction-Tolerance, Non Steroidal Anti Inflammatory Drugs, Sickle Cell Disease}

\section{Introduction}

The sickle cell disease is a genetic pathology due to a hemoglobin abnormality. Its prevalence in Ivorian is estimated to $14 \%$ [1] [2]. This pathology is often characterized by hemolytic anemia and or vaso-occlusive painful crisis due to the presence of bloked capillaries. Such mechanism induces a locally inflammatory process which justifies the use of non steroidal anti inflammatory drugs (NSAIDs) in the treatment. NSAIDs are widely described drugs for treatment of pain, fever, arthritis or other inflammatory diseases because of their high safety profile [3]. In Abidjan's school, these drugs are becoming essential in the treatment of the painful crisis of sickle cell disease and no codified alternative therapeutic seems to be used to our knowledge. Unfortunately, the use of NSAIDs may be accompanied by intolerance reactions of the skin (urticaria, angio-oedema, pruritus, flush), respiratory symptoms (dyspnoea, rhinitis) or anaphylactic-like reactions [4] [5]. The manifestations usually occur within 3 hours after drug intake [6]. NSAID intolerance is one of the most common causes of adverse drug reactions (ADRs) accounting for 44.7\% of all reported ADRs, only surpassed by ADRs induced by antimicrobials [7] [8]. The prevalence of adverse reactions to NSAIDs is about $0.3 \%-0.9 \%$ whereas in the normal population it amounts to $23 \%-28 \%$ in patients with asthma and chronic urticaria [9]-[12].

In a previous study, $15 \%$ of respiratory syndroms (asthma, rhinitis or dyspnoea) were associated to NSAID intake in patients suffering from sickle cell disease [13]. These patients are paradoxically constrained to take NSAIDs during the vaso-occlusive crisis. They are exposed to adverse reactions. The objective of this work is to evaluate the effectiveness of a rapid protocol of a tolerance induction to NSAIDs.

\section{Materiel and Methods}

\subsection{Patients}

A total of 22 patients expressing following phenotypes of sickle cell disease (SC, SSFA2, SFA2 - 15 men and 7 women) aged from 12 to 39 years (age mean: $22.41 \pm 7.88$ ) were enrolled. They have been selected among 1500 patients followed up in the department of Immunology-Hematology and Allergology of CHU Cocody-Abidjan. Patients were included after giving informed consent to the protocol approved by the ethical committee of Côte d'Ivoire. None of the patients had taken antihistamine (within the last 3 days) or corticosteroid medication (within the last 14 days) before the procedure. All patients were known to have a documented history of at least one episode of adverse reactions following the intake of Ibuprofen or Diclofenac whereas none of them had a history of infection, adverse gastrointestinal side effects, chronic renal failure and other kidney diseases, and liver diseases. The induced clinical syndroms summarized in Table 1 were treated using intravenous corticosteroid. In our study we did not perform any oral challenge test for the diagnosis of allergy to NSAID because of the severity of the clinical syndroms; however the occurrence of NSAID intake signs following the treatment of the pain was the evidence of such diagnosis.

\subsection{Skin Tests and Desensitization Evidence}

Skin tests were performed by prick method. This test was performed to evaluate the sensitivity of each patient to NSAIDs and to determine minimal doses inducing reactions that will be taken as the initial dose in the tolerance induction protocol. Consequently, before the procedure and one (M1), six (M6) months after the procedure, daily doses of Ibuprofen $(1200 \mathrm{mg})$ and Diclofenac $(150 \mathrm{mg})$ geometrically diluted with distilled water were tested in each patient. The results were compared to the histamine positive control $(10 \mathrm{mg} / \mathrm{ml})$ as well as to the distilled water negative control.

We have limited the induction of tolerance to NSAID to the lack of clinical syndroms during the treatment of the painful crisis since skin test is not an evidence of desensitization and the oral challenge test was not performed because of the severity of the induced clinical signs. 
Table 1. The clinical syndroms induced by NSAIDs intake before the tolerance induction procedure.

\begin{tabular}{|c|c|c|c|c|c|c|c|}
\hline $\mathrm{N}^{\circ}$ & Age $^{*}$ & Sex & Weight $^{* *}$ & $\mathrm{Hb}^{* * *}$ & NSAID & Clinical Syndroms & Within the time limit \\
\hline \multicolumn{8}{|c|}{ Group Ai } \\
\hline 01 & 21 & $\mathrm{~F}^{\ddagger}$ & 52 & SC & $\mathrm{ibu}^{\dagger}$ & Rhinitis/pruritus/angio-oedema & within $15 \mathrm{mn}$ \\
\hline 02 & 16 & $\mathrm{M}^{\#}$ & 45 & SC & ibu & Rhinitis/asthma & within 15 to $30 \mathrm{mn}$ \\
\hline 03 & 19 & $\mathrm{~F}$ & 52 & SC & ibu & Hypotension/dyspnoea & within $15 \mathrm{mn}$ \\
\hline 04 & 13 & $\mathrm{~F}$ & 41 & SAFA2 & ibu & Angio-oedema & up to 6 hours \\
\hline 05 & 30 & M & 58 & SSFA2 & ibu & Angio-oedema/dyspnoea & within $15 \mathrm{mn}$ \\
\hline 06 & 19 & M & 51 & SC & ibu & Asthma/rhinitis & within $15 \mathrm{mn}$ \\
\hline 07 & 15 & $\mathrm{~F}$ & 43 & SSFA2 & ibu & Hypotension/dyspnoea & up to 1 hour \\
\hline 08 & 30 & M & 52 & SSFA2 & ibu & Asthma/rhinitis & within $15 \mathrm{mn}$ \\
\hline 09 & 33 & M & 57 & SAFA2 & ibu & Rhinitis/pruritus/angio-oedema & within $15 \mathrm{mn}$ \\
\hline 10 & 16 & M & 50 & SC & ibu & Hypotension/dyspnoea & within $15 \mathrm{mn}$ \\
\hline 11 & 14 & M & 45 & SSFA2 & ibu & Rhinitis/pruritus/angio-oedema & within 15 to $30 \mathrm{mn}$ \\
\hline \multicolumn{8}{|c|}{ Group Bd } \\
\hline 12 & 18 & M & 51 & SC & $\operatorname{dicl}^{\dagger \dagger}$ & Asthma/rhinitis & within 15 to $30 \mathrm{mn}$ \\
\hline 13 & 39 & M & 61 & SSFA2 & dicl & Angio-oedema/pruritus & within $30 \mathrm{mn}$ to 1 hour \\
\hline 14 & 27 & $\mathrm{~F}$ & 55 & SC & dicl & Dyspnoea & within 15 to $30 \mathrm{mn}$ \\
\hline 15 & 20 & $\mathrm{~F}$ & 48 & SAFA2 & dicl & pruritus/Hypotension/dyspnoea & within 15 to $30 \mathrm{mn}$ \\
\hline 16 & 28 & M & 59 & SC & dicl & Hypotension/dyspnoea & within 15 to $30 \mathrm{mn}$ \\
\hline 17 & 29 & $\mathrm{~F}$ & 61 & SC & dicl & Hypotension/dyspnoea & within $15 \mathrm{mn}$ \\
\hline 18 & 12 & M & 38 & SAFA2 & dicl & Hypotension/dyspnoea & within $15 \mathrm{mn}$ \\
\hline 19 & 33 & M & 58 & SC & dicl & Rhinitis & within $15 \mathrm{mn}$ \\
\hline 20 & 15 & M & 42 & SSFA2 & dicl & Asthma & within $15 \mathrm{mn}$ \\
\hline 21 & 21 & M & 46 & SSFA2 & dicl & Rhinitis/pruritus/angio-oedema & within $30 \mathrm{mn}$ to 1 hour \\
\hline 22 & 35 & M & 57 & SSFA2 & dicl & Asthma & within $30 \mathrm{mn}$ to 1 hour \\
\hline
\end{tabular}

\subsection{Tolerance Procedure}

The tolerance induction protocol was carried out at the Allergy Unit of the department of Immunology-Hematology and Allergology of CHU Cocody-Abidjan in the 22 patients divided into two randomized subgroups (A, B) containing 11 patients. One NSAID was allotted to each subgroup according to the procedure indicated in Table 1 (Ai: Group A ibuprofen. Bd: Group B Diclofenac). At day 1 (D1), day 2 and day 3 (D2, D3), all the patients were hospitalized respectively during 14 and 8 hours in the Allergy Unit of our department. Before and during the tolerance procedure, cardiovascular parameters, naso ocular, pulmonary, and cutaneous symptoms were monitored in all patients. In patients with a history of bronchial asthma or respiratory symptoms induced after NSAID intake, a pulmonary function test was performed before the beginning of the procedure. The oral initial dose (diluted in distilled water) was the lowest that have given a positive reaction to the prick-test carried out before the procedure (8.82 $\mathrm{mg}$ for Ibuprofen and $2.20 \mathrm{mg}$ for Diclofenac). We gradually increased every 60 minutes to reach in 6 hours later the effective therapeutic dose. The first day (D1), this last dose was renewed 6 hours later. The second (D2) and third (D3) days, the therapeutic dose has been orally administrated with an interval of 6 hours during 12 hours as indicated in Table 2. 
Table 2. Our tolerance induction protocol to Ibuprofen and Diclofenac.

\begin{tabular}{|c|c|c|c|}
\hline & \multirow{2}{*}{$\begin{array}{c}\text { Days }(D) \\
\text { Time of administration (H: hour) }\end{array}$} & \multicolumn{2}{|c|}{ Cumulative doses (mg) } \\
\hline & & Ibuprofen & Diclofenac \\
\hline \multirow[t]{7}{*}{$D 1$} & HO & 8.82 & 2.20 \\
\hline & H1 & 17.625 & 4.40 \\
\hline & $\mathrm{H} 2$ & 35.25 & 8.8125 \\
\hline & H3 & 75 & 17.625 \\
\hline & $\mathrm{H} 4$ & 150 & 35.25 \\
\hline & H6 & 400 & 50 \\
\hline & H12 & 800 & 100 \\
\hline \multicolumn{4}{|c|}{$D 2$} \\
\hline & $\mathrm{HO}$ & 400 & 50 \\
\hline & H6 & 800 & 100 \\
\hline & H12 & 1200 & 150 \\
\hline \multicolumn{4}{|l|}{ D3 } \\
\hline & $\mathrm{HO}$ & 400 & 50 \\
\hline & H6 & 800 & 100 \\
\hline & H12 & 1200 & 150 \\
\hline
\end{tabular}

During and after the challenge test, patients remained under medical supervision for up to 120 minutes. When objective symptoms summarized in Table 3 (flush, urticaria, angio-oedema, rhinitis, conjunctivitis, dyspnoea or cough and asthma crisis, hypotension) appeared, patient was adequately treated and declared ineligible for at least 6 months before he could be convoked for another appointment. Three days after the procedure, patients out of hospital could contact us by telephone to report any reliable symptoms that might appear.

\subsection{Statistical Analysis}

The Chi-Square test by Pearson was used to analyze our data and a p value $=0.05$ was considered significant (SPSS for Windows, version 10.0).

\section{Results}

The patients were classified according to the NSAID (Group I for those who have taken Ibuprofen and Group D for Diclofenac). The two NSAIDs were prescribed independently of the age (22.41 \pm 7.88 years), of the sex (sex ratio 1.6 man for 1 woman), of the weight (middleweight of the patients with $51 \mathrm{Kg}$ ) and of the hemoglobin phenotype. All the patients have a history of clinical symptoms that occurred 15 minutes to 24 hours later NSAID intake. The symptoms summarized in Table 1 were anaphylactic reactions associating hypotension, cardiovascular shock, according to EAACI revised nomenclature for allergy [14]. Few symptoms have occurred more than 1 hour after the NSAID intake.

The tolerance induction protocol to the NSAID was extended over three days. Table 2 shows times of administration of the drugs and their cumulative doses. No lost sight was observed. 72 hours after the end of the procedure, hypo responsiveness was induced in $76 \%, 84 \%$ and $88 \%$ of the patients respectively at D1, D2-D3 (Table 3). No objective symptoms appeared. However, apart from the epigastralgia that may be linked to the gastrotoxicity documented of NSAID, we noted 6, 4, and 3 cases of failure respectively at D1, D2-D3 (Table 4). Two syndrom groups were observed: the group of Asthma/Rhinitis that contained 11 cases out of the 22 patients. Among those patients, 2 cases of tolerance failure represented $9.1 \%$ with an eczema that appeared at 72 
Table 3. Clinical and skin tests results of the tolerance procedure in each patient.

\begin{tabular}{|c|c|c|c|c|c|c|c|c|c|}
\hline No & Drug & Pric & $\mathrm{k} 1^{\S}$ & Syndroms $1^{\S \S}$ & $\underset{2^{\S \S \S}}{\text { Syndroms }}$ & $\begin{array}{c}\text { Syndroms } \\
3^{\S \S \S \S}\end{array}$ & $\begin{array}{c}\text { Syndroms } \\
4 \|\end{array}$ & $\begin{array}{c}\text { CS/Prick } \\
2^{4}\end{array}$ & $\underset{3^{\text {fif }}}{\text { CS/Prick }}$ \\
\hline & & ibu & dicl & & & & & & \\
\hline 01 & ibu & + & - & Rhinitis/pruritus/angio-oedema & none & none & none & - & - \\
\hline 02 & ibu & + & - & Rhinitis/asthma & none & none & none & - & \\
\hline 03 & ibu & + & - & Hypotension/dyspnoea & none & none & none & - & - \\
\hline 04 & ibu & + & - & Angio-oedema & none & none & none & - & - \\
\hline 05 & ibu & - & + & Angio-oedema/dyspnoea & Epigastric pain & Epigastric pain & none & + dicl & - \\
\hline 06 & ibu & + & - & Asthma/rhinitis & Asthma/rhinitis & Rhinitis & Eczema & $+\mathrm{ibu}$ & - \\
\hline 07 & ibu & + & - & Hypotension/dyspnoea & Hypotension/dyspnoea & none & none & - & - \\
\hline 08 & ibu & - & + & Asthma/rhinitis & none & none & none & - & - \\
\hline 09 & ibu & + & - & Rhinitis/pruritus/angio-oedema & Angio-oedema & none & none & - & - \\
\hline 10 & ibu & + & - & Hypotension/dyspnoea & Pruritus & none & Rhinitis & $+\mathrm{ibu}$ & $+\mathrm{ibu}$ \\
\hline 11 & ibu & - & + & Rhinitis/pruritus/angio-oedema & none & none & none & - & - \\
\hline 12 & dicl & - & + & Asthma/rhinitis & none & none & none & - & - \\
\hline 13 & dicl & + & - & Angio-oedema/pruritus & none & none & none & - & - \\
\hline 14 & dicl & + & - & Dyspnoea/ & none & none & none & - & - \\
\hline 15 & dicl & - & + & Pruritus/hypotension/dyspnoea & none & none & none & - & - \\
\hline 16 & dicl & - & - & Hypotension/dyspnoea & Hypotension/dyspnoea & none & Hypotension & - & - \\
\hline 17 & dicl & + & - & Hypotension/dyspnoea & none & none & none & - & - \\
\hline 18 & dicl & + & - & Hypotension/dyspnoea & Angio-oedema & Pruritus & none & - & $+\mathrm{ibu}$ \\
\hline 19 & dicl & - & + & Rhinitis & none & none & none & - & - \\
\hline 20 & dicl & - & - & Asthma & Rhinitis & Rhinitis & Pruritus/rhinitis & - & - \\
\hline 21 & dicl & + & - & Rhinitis/pruritus/angio-oedema & none & none & none & - & - \\
\hline \multirow[t]{2}{*}{22} & dicl & + & - & Asthma & none & none & none & - & - \\
\hline & \multicolumn{4}{|r|}{ Level of tolerance } & $76 \%$ & $84 \%$ & $88 \%$ & $88 \%$ & $92 \%$ \\
\hline
\end{tabular}

Table 4. Comparison of the tolerance level to NSAIDs according to the severity of syndroms.

\begin{tabular}{|c|c|c|c|c|}
\hline \multirow[t]{2}{*}{ Group syndrom } & \multicolumn{4}{|c|}{ Number of patients Number and proportion of patients tolerating NSAIDs } \\
\hline & D. $0^{\text {19\% }}$ & D1 & D2-D3 & $\mathrm{H} 72^{\|\|}$ \\
\hline Asthma/rhinitis & $11 / 22$ & $9 / 11(18.18 \%)$ & $9 / 11(18.18 \%)$ & 9/11 (18.18\%) \\
\hline Anaphylactic reactions (pruritus, angioedema) & $5 / 22$ & $4 / 5(20 \%)$ & $5 / 5(100 \%)$ & $5 / 5(100 \%)$ \\
\hline Anaphylactic reactions (hypotension, cardiovascular shock) & $6 / 22$ & 2/6 (33.33\%) & $5 / 6(83.4 \%)$ & $4 / 6(66.66 \%)$ \\
\hline
\end{tabular}

१ศศ : Before tolerance induction procedure; " II: H72 after procedure.

hours after D3 (three days after the procedure) and confirmed by a positive patch test to Ibuprofen in patients $n^{\circ}$ 6 , and 20. The second group was composed of anaphylactic syndroms. On the one hand, from 5 patients out of 
22 having a history of anaphylactic reactions such as pruritus and angioedema occurring after NSAIDs intake, one of them (4.54\%) had presented angioedema at D1. The results have been confirmed 1 and 6 months later by the negative skin tests as well as by the lack of clinical syndroms following the treatment of the painful crisis using Diclofenac or Ibuprofen (this might suggest a negative oral challenge test).

On the other hand, among patients with a history of anaphylactic reactions such as symptoms associating hypotension, cardiovascular shock, the NSAID was not tolerated in $4(18.18 \%), 1(4.54 \%)$ and $2\left(9.1 \%\right.$; $n^{\circ} 10$, and 16) patients respectively at the D1, D2-D3 of the procedure and 72 hours after the end of the procedure. At M1 and M6, a positive result of prick test in patient $\mathrm{n}^{\circ} 10$ was observed.

This was associated with a persistence of clinical syndroms whereas in patients $n^{\circ} 16$, and 20 of asth$\mathrm{ma} / \mathrm{rhinitis}$ group, cutaneous test remained negative without no clinical syndroms. According to the number of NSAID intake days, a significant increase of tolerance was observed as showed in Table 3 (tolerance level was $76 \%$ vs $84 \%$ vs $88 \%$ respectively at D1, D2-D3, and 72 hours after the end of the procedure; $p<0.05$ ). In contrast, comparative analysis revealed a decrease level of tolerance according to the severity of the syndroms (the global level of tolerance was lower in the groups of anaphylaxis associating hypotension cardiovascular shock and anaphylaxis with pruritus, angioedema than in the group of asthma/rhinitis; Table 4, $\mathrm{p}<0.05$ ).

\section{Discussion}

The treatment of the inflammation induced in the vaso-occlusive painful crisis of the sickle cell disease requires usually the NSAIDs. Unfortunately, NSAIDs are after antibiotics, the second most frequently suspected agents causing drug hypersensitivity [15]. Indeed, these drugs are responsible for $21 \%-25 \%$ of reported adverse drug events which include immunologic and non-immunologic hypersensitivity reactions [16]. The prevalence of acetyl salicylic acid (ASA, aspirin) hypersensitivity ranges from $0.6 \%$ to $2.5 \%$ in the general population, from $4.3 \%$ to $11 \%$ in asthmatic patients [17] and from 20 to $40 \%$ in chronic idiopathic urticaria [18]. The hypersensitivity may occur shortly, within 15 minutes or longer, up to 24 hours after NSAID intake. In general it develops within 1 to 4 hours [19]. Some patients might have life-threatening reactions, especially those with aspirin exacerbated respiratory diseases (AERDs, Widal syndrome), which associate aspirin sensitivity, asthma, nasal polyposis, and the airway remodeling [17]. Few subtypes of hypersensitivity to NSAIDs are recognized depending on timing, symptomatology and putative mechanism of reactions [20]-[22]: NSAID-exacerbated respiratory disease designated as aspirin-exacerbate respiratory disease; NSAID or aspirin-exacerbated cutaneous disease (urticaria and angioedema in patients with chronic idiopathic urticaria); Multiple NSAID-triggered urticaria, angioedema, and anaphylaxis in patients without other underlying disease; Urticaria, angioedema, and anaphylaxis induced by a single NSAID. In turn these can be divided into IgE or T cell dependent reactions [23]. In 70\% of cases, non-specific immunological mechanism is involved in the NSAID hypersensitivity [24]. Eicosanoid metabolism dysfunction or other alterations are prone to hypersensitivity when NSAIDs inhibit the enzyme cylooxygenase-1 (Cox-1) [19] [25]. Selective NSAIDs strongly inhibit COX-2, but they are weak inhibitors of COX-1, so they are well tolerated in patients with NSAID-sensitive asthma [26] [27]. Only in 1/3 of the cases will be theoretically possible to apply in vivo or in vitro specific immunological tests based on the capacity of IgE or T cells [28].

In our patients, the immunological mechanism may likely be evoked. Indeed, the majority of the patients were enlisted on the basis of positive skin test as well as on the clinical syndroms induced by NSAID intake. The NSAID-induced clinical syndroms such as asthma/rhinitis and anaphylaxis are generally associated to immediate hypersensitivity (IgE hypersensitivity) according to Gell and Coombs's classification [13]. In addition, clinical signs appeared in less than 2 hours after NSAID intake and were associated to a positive skin test to Diclofenac or Ibuprofen. In contrast, in patients displaying the negative cutaneous test, the Eicosanoid metabolism dysfunction might be involved. Indeed, it is known that controlled oral challenge test is the only definitive way to detect sensitivity to non-steroidal anti-inflammatory drugs in patients with adverse reactions to these agents [29]. Nevertheless, due to the severity of the induced clinical signs, we limited the NSAIDs hypersensitivity diagnosis to the skin test but not to oral challenge test (in the management of the painful crisis, the occurrence or the lack of the clinical syndrom following the NSAID intake might be considered as a confirmation or infirmation of the diagnosis of hypersensitivity to NSAID).

In general, patients who have adverse reactions to nonselective NSAIDs have limited analgesic and anti-inflammatory therapeutic options, but several studies have shown that highly selective cyclo-oxygenase-2 (COX-2) 
inhibitors can be safely used [30] [31]. However, in a small percentage of cases, adverse reactions (respiratory or cutaneous) have been observed during a challenge with a COX-2 inhibitor [32]. When these occur, the next step to be taken is not clear [33]. And particularly in patients suffering from sickle cell disease, none codified alternative therapeutic is known.

Certainly, at the time of crisis, the patient needs to be treated for pain. However the analgesic therapeutic option is often ineffective in our experience. Consequently the desensitization to NSAIDs might be proposed because of the inflammatory process involved in the pain. In these patients, it was necessary to develop a protocol allowing NSAIDs to be safely administered in a few hours to treat the painful crisis.

We evaluated the results of immune tolerance of two NSAIDs within a rapid tolerance protocol as performed elsewhere [34]. Whatever the NSAID, all patients have presented the same clinical signs reported in Table 1, before the study. Six month later, we noted that $88 \%$ of patients have tolerated Diclofenac or Ibuprofen.

Nevertheless, few cases of failure have been reported. Such cases might be related either to severity of clinical signs or to the patho-physiological mechanism involved. Indeed, pharmacological profiles as well as hypersensitivity of NSAIDs depend on their inhibitory activities. It is known that the diagnosis of hypersensitivity to NSAID is based on the clinical history, the skin test and the oral provocation challenge test with NSAIDs [35] [36]. The skin test responses are typically negative except when there is a true allergy [15]. In our study, failure cases were observed in patients suffering from severe syndroms (asthma/rhinitis and anaphylaxis syndrom) [17]. In addition, the fact that skin tests were negative before tolerance induction in patients $n^{\circ} 16$ and 20 (Tables 1 and 3) may demonstrated the involving of the dysfunction of the mechanism of eicosanoid metabolism in such tolerance failure. Furthermore it is now also known that tolerance induction can be used in for non-IgE mediated allergic reactions [37], and the protocols of desensitization to the NSAIDs and acetylsalicylic acid showed well performances [38]. Anyway, the mechanism of the tolerance remains an immunological base [37]. Various studies have proposed different mechanisms for IgE-mediated desensitization: internalization of antigen/IgE/FCERI and cross-linking of inhibitory receptors on mast cells [39]; reduced levels of up-stream signal transducing molecules, such as Syk which are necessary for activation and mast cell IgE-signalling [8]; negative regulation of IgE mediated allergic responses by Lyn kinase in mast cell responses both in vivo and in vitro [40]; and elevated levels of the signal transducer and transcriptor activator STAT-6 involved in transcription of IL-4 and IL-13 necessary for desensitization of murine mast cells [41] [42]. In the food allergy, desensitization is the result of particular immunological mechanisms located in the intestinal mucous: specific T-cells deletion, anergy or inhibiting control is exerted by T-cells regulators. These cells (essentially CD4+) that comprised various lymphocyte sub population expressing CD4 + CD25 + Foxp $3+$ and generated in thymus and the periphery, Th3 cells producing TGF-beta and Tr1 producing IL-10 are cells involved in the immunological mechanism of desensitization [43] [44].

These cell subpopulations are generated by the oral administration of the antigens. They are known to be involved in the inhibition of $\mathrm{T}$ cells effector activation, the inhibition of specific-IgE induction and the IgE-dependent allergy inflammation [44]. It has been demonstrated that tolerance cannot be induced in mice CD4 + CD25 + T regulators knock out [45].

Anyway, such rapid protocol did not allow us to conclude that the tolerance obtained in our patients had an immunological mechanism as describe above since the patients weren't tested at a long enough interval.

Several reasons led us to perform a rapid tolerance protocol. On one hand, there is a lack of recommendations for the clinical and immunological follow-up on the long-term. Many different protocols have been published, from 3 days (rush milk oral immunotherapy) [46] [47] to a 6 month protocols (slow dose-up oral immunotherapy) [48]. Any study both comparing different oral immunotherapy regimens and defining different patient's phenotypes in order to perform oral immunotherapy was known.

On the other hand, rapid protocol has proved its effectiveness in others studies. Szczeklik and Stevenson described a strategy for the desensitization of patients who have respiratory disease exacerbated by aspirin This protocol, which is also known as the "Scripps Clinical Protocol", includes small oral doses of aspirin that are administered over 2 to 3 days, up to 400 - $650 \mathrm{mg}$. Aspirin desensitization, followed by daily aspirin treatment, can be considered as a therapeutic option in patients with aspirin-exacerbated respiratory disease who suffer from chronic coronary artery disease [49].

More recently, Rossini et al. used a different protocol for rapid desensitization in 26 patients with a history of hypersensitivity to aspirin who were to undergo a coronary intervention with stent implantation and had shown aspirin sensitivity in the past, with respiratory or cutaneous reactions. The procedure included the administration 
of 6 progressively increasing doses of aspirin $(1,5,10,20,40$ and $100 \mathrm{mg})$ over 5.5 hours. Of the 23 patients who were desensitized successfully, 22 received stents and took aspirin for 1 year without showing any adverse effects, apart from 1 who discontinued the treatment because of a peptic ulcer [50].

In our study, the results of the cutaneous tests to the NSAIDs assessed and NSAID intake clinical syndroms before the induction of the tolerance in patients $\mathrm{n}^{\circ} 6$, and 10 , might well demonstrate the diagnosis of IgE-mediated allergy. However the failure of tolerance in these two patients remains unexplained. In spite of these failures, general analysis of the results shows the success of our protocol even if the mechanisms of such tolerance remain unknown.

\section{Conclusion}

The use of NSAIDs in the painful crisis of sickle cell disease may induce intolerance to such drugs. The Eicosanoid metabolism dysfunction mechanism is often reported to be associated with adverse syndroms whereas IgEdependant allergy mechanism might be involved too. However, in front of the lack of an alternative therapeutic to treat the painful crisis, such successful tolerance induction protocol to NSAID might be proposed. In addition, this experience could be used in other pathologies in our context where patients often develop intolerance to antibiotics such as sulfonamide in HIV infection. Indeed, patients infected with HIV are at increasing risk of developing cutaneous reactions to sulfonamide antibiotics. This is likely related to immunologic factors and frequent exposure to these antibiotics. Trimethoprim-sulfamethoxazole (TMP-SMX) is the drug of choice for the treatment of a number of HIV-associated infections and, therefore, many HIV-positive patients with a history of reacting to sulfonamides still require treatment with this antibiotic. Induction of drug tolerance procedures can be used to safely administer TMPSMX to HIV-positive patients with a history of reacting to the antibiotic [51].

\section{Conflict of Interests}

The authors state no conflict of interests.

\section{Authors' Contribution}

R. Dasse conceptualized and designed the study. R Dasse and K. Amah drafted the manuscript. FM Sombo, AD Paul, K. Nguessan and R. Yeboah critically reviewed it and contributed to its design. All authors participated to revise the different draft versions and approved the final manuscript.

\section{Acknowledgements}

The authors appreciate the contribution of Immunology-Hematology-Allergology department of CHU CocodyAbidjan (Côte d'Ivoire). They acknowledge the essential collaboration of Nguessan Emmanuel for the skin test assessment. Special thanks to the nurses of our allergy unit for their help. This study was not funded.

\section{References}

[1] La drépanocytose, C.R. (1973) Medicorama. 27-30.

[2] Cabanne, R., Sangaré, A., et al. (1987) La prise en charge du drépanocytaire: l'expérience Ivoirienne. Annual University Abidjan série médi. 149-197.

[3] American College of Rheumatology Ad Hoc Committee on Clinical Guidelines (1996) Guidelines for the Management of Rheumatoid Arthritis. Arthritis \& Rheumatology, 39, 713-722.

[4] Christie, P.E., Smith, C., Arm, J.P. and Lee, T.H. (1992) Aspirin Sensitive Asthma. Clinical \& Experimental Allergy, 22, 171-175. http://dx.doi.org/10.1111/j.1365-2222.1992.tb03069.x

[5] Slepian, I.K., Mathews, K.P. and McLean, J.A. (1985) Aspirin-Sensitive Asthma. Chest, 87, 386-391. http://dx.doi.org/10.1378/chest.87.3.386

[6] Yates, A.B. and de Shazo, R.D. (2003) Allergic and Non-Allergic Drug Reactions. South Medical Journal, 96, 10801087. http://dx.doi.org/10.1097/01.SMJ.0000097888.70112.52

[7] Naldi, L., Conforti, A., Venegoni, M., Troncon, M.G., Caputi, A., Ghiotto, E., et al. (1999) Cutaneous Reactions to Drugs. An Analysis of Spontaneous Reports in Four Italian Regions. British Journal of Clinical Pharmacology, 48, 839-846. http://dx.doi.org/10.1046/j.1365-2125.1999.00096.x 
[8] Namazy, J.A. and Simon, R.A. (2002) Sensitivity to Nonsteroidal Anti-Inflammatory Drugs. Annals of Allergy, Asthma \& Immunology, 89, 542-550.

[9] Settipane, G.A. (1988) Aspirin Sensitivity and Allergy. Biomed Pharmacotherapy, 42, 493-498.

[10] Hoigne, R., Schlumberger, H.P., Vervloet, D. and Zoppi, M. (1993) Epidemiology of Allergic Drug Reactions. Monographs in Allergy, 31, 147-170.

[11] Sánchez-Borges, M. (2008) Clinical Management of Non-Steroidal Anti-Inflammatory Drug Hypersensitivity. WAO Journal, 1, 29-33.

[12] Jenneck, C., Juergens, U., Buecheler, M. and Novak, N. (2007) Pathogenesis, Diagnosis, and Treatment of Aspirin Intolerance. Annals of Allergy, Asthma \& Immunology, 99, 13-21. http://dx.doi.org/10.1016/S1081-1206(10)60615-1

[13] Romuald, D.S., Koffi, N., Paul, A.D., Rita, Y. and François, S.M. (2011) Manifestations respiratoires induites par les anti-inflammatoires non stéroïdiens chez le drépanocytaire. Sante, 21, 187-191.

[14] Johansson, S.G.O., O’B Hourihane, J., Bousquet, J., Bruijnzeel-Koomen, C., Dreborg, S., Haahtela, T., Kowalski, M.L., Mygind, N., Ring, J., van Cauwenberge, P., van Hage-Hamsten, M. and Wüthrich, B. (2001) A Revised Nomenclature for Allergy: An EAACI Position Statement from the EAACI Nomenclature Task Force. Allergy, 56, 813-824. http://dx.doi.org/10.1034/j.1398-9995.2001.t01-1-00001.x

[15] Abuaf, N., Rostane, H., Barbara, J., Toly-Ndour, C., Gaouar, H., Mathelier-Fusade, P., Leynadier, F., Francès, C. and Girot, R. (2012) Comparison of CD63 Upregulation Induced by NSAIDs on Basophils and Monocytes in Patients with NSAID. Journal of Allergy (Cairo), 2012, 580873. http://dx.doi.org/10.1155/2012/580873

[16] Kowalski, M.L., Makowska, J.S., Blanca, M., Bavbek, S., Bochenek, G., Bousquet, J., Bousquet, P., Celik, G., Demoly, P., Gomes, E.R., Nizankowska-Mogilnicka, E., Romano, A., Sanchez-Borges, M., Sanz, M., Torres, M.J., De Weck, A., Szczeklik, A. and Brockow, K. (2011) Hypersensitivity to Non-Steroidal Anti-Inflammatory Drugs (NSAIDs)-Classification, Diagnosis and Management: Review of the EAACI/ENDA and GA2LEN/HANNA. Allergy, 66, 818-829. http://dx.doi.org/10.1111/j.1398-9995.2011.02557.x

[17] Kasper, L., Sladek, K., Duplaga, M., et al. (2003) Prevalence of Asthma with Aspirin Hypersensitivity in the Adult Population of Poland. Allergy, 58, 1064-1066. http://dx.doi.org/10.1034/j.1398-9995.2003.00267.x

[18] Juhlin, L. (1981) Recurrent Urticaria: Clinical Investigation of 330 Patients. British Journal of Dermatology, 104, 369381. http://dx.doi.org/10.1111/j.1365-2133.1981.tb15306.x

[19] Setkowicz, M., Mastalerz, L., Podolec-Rubis, M., Sanak, M. and Szczeklik, A. (2009) Clinical Course and Urinary Eicosanoids in Patients with Aspirin-Induced Urticaria Followed up for 4 Years. Journal of Allergy and Clinical Immunology, 123, 174-178. http://dx.doi.org/10.1016/j.jaci.2008.09.005

[20] Szczeklik, A., Nizankowska-Mogilnicka, E. and Sanak, M. (2009) Hypersensitivity to Aspirin and Nonsteroidal AntiInflammatory Drugs. In: Adkinson Jr., N.F., Bochner, B.S., Busse, W.W., Holgate, S.T., Lemanske Jr., R.F. and Simons, F.E.R., Eds., Middleton's Allergy: Principles and Practice, 7th Edition, Mosby Elsevier, New York, 1227-1243.

[21] Stevenson, D.D., Sanchez-Borges, M. and Szczeklik, A. (2001) Classification of Allergic and Pseudoallergic Reactions to Drugs that Inhibit Cyclooxygenase Enzymes. Annals of Allergy, Asthma \& Immunology, 87, 177-180. http://dx.doi.org/10.1016/S1081-1206(10)62221-1

[22] Makowska, J.S., Grzegorczyk, J., Bienkiewicz, B., Wozniak, M. and Kowalski, M.L. (2008) Systemic Responses after Bronchial Aspirin Challenge in Sensitive Patients with Asthma. Journal of Allergy and Clinical Immunology, 121, 348-354. http://dx.doi.org/10.1016/j.jaci.2007.09.039

[23] Pérez-Calderón, R., Gonzalo-Garijo, M.A., Pérez-Rangel, I., Sánchez-Vega, S. and Zambonino, M.A. (2011) Fixed Drug Eruption Due to Nabumetone in a Patient with Previous Fixed Drug Eruptions Due to Naproxen. Journal of Investigational Allergology and Clinical Immunology, 21, 153-154.

[24] Kim, H.A., Ye, Y.M., Kim, S.H., Hur, G.Y. and Park, H.S. (2007) Association of $\beta 2$-Adrenergic Receptor Polymorphism with the Phenotype of Aspirin-Intolerant Acute Urticaria. Yonsei Medical Journal, 48, 1079-1081. http://dx.doi.org/10.3349/ymj.2007.48.6.1079

[25] Kim, Shin-Hyun, Choi, J.H., Lee, K.W., Kim, Se-Heon, Shin, E.S., Oh, H.B., Suh, C.H., Nahm, D.H. and Park, H.S. (2005) The Human Leucocyte Antigen-DRB1*1302-DQB1*0609-DPB1*0201 Haplotype May be a Strong Genetic Marker for Aspirin-Induced Urticaria. Clinical and Experimental Allergy, 35, 339-344. http://dx.doi.org/10.1111/j.1365-2222.2004.02197.x

[26] Stevenson, D.D. and Simon, R.A. (2001) Lack of Cross-Reactivity between Rofecoxib and Aspirin in Aspirin-Sensitive Patients with Asthma. Journal of Allergy and Clinical Immunology, 108, 47-51. http://dx.doi.org/10.1067/mai.2001.116290

[27] Zembowicz, A., Mastalerz, L., Setkowicz, M., Radziszewski, W. and Szczeklik, A. (2003) Safety of Cyclooxygenase 2 Inhibitors and Increased Leukotriene Synthesis in Chronic Idiopathic Urticaria with Sensitivity to Nonsteroidal AntiInflammatory Drugs. JAMA Dermatology, 139, 1577-1582. http://dx.doi.org/10.1001/archderm.139.12.1577 
[28] Gómez, E., Jose Torres, M., Mayorga, C. and Blanca, M. (2012) Immunologic Evaluation of Drug Allergy. Allergy, Asthma \& Immunology Research, 4, 251-263.

[29] Quiralte, J., Blanco, C., Delgado, J., Ortega, N., Alcntára, M., Castillo, R., Anguita, J.L., Sáenz de San Pedro, B. and Carrillo, T. (2007) Challenge-Based Clinical Patterns of 223 Spanish Patients with Nonsteroidal Anti-InflammatoryDrug-Induced-Reactions. Journal of Investigational Allergology \& Clinical Immunology, 17, 182-188.

[30] Dahlen, B., Szczeklik, A. and Murray, J.J. (2001) Celecoxib in Patients with Asthma and Aspirin Intolerance. New England Journal of Medicine, 344, 142. http://dx.doi.org/10.1056/NEJM200101113440215

[31] Sanchez-Borges, M., Caballero-Fonseca, F. and Capriles-Hulett, A. (2005) Safety of Etoricoxib, a New Cyclooxygenase 2 Inhibitor, in Patients with Nonsteroidal Anti-Inflammatory Drug-Induced Urticaria and Angioedema. Annals of Allergy, Asthma \& Immunology, 95, 154-158. http://dx.doi.org/10.1016/S1081-1206(10)61205-7

[32] Weberschock, T.B., Muller, S.M., Boehncke, S. and Boehncke, W.H. (2007) Tolerance to Coxibs in Patients with Intolerance to Non-Steroidal Anti-Inflammatory Drugs (NSAIDs): A Systematic Structured Review of Literature. Archives of Dermatological Research, 299, 169-175. http://dx.doi.org/10.1007/s00403-007-0757-6

[33] Cimbollek, S., Quiralte, J. and Avila, R. (2009) COX-2 Inhibitors in Patients with Sensitivity to Nonselective NSAIDs. New England Journal of Medicine, 361, 2197-2198. http://dx.doi.org/10.1056/NEJMc0907208

[34] Christou, A., Kafkas, N., Marinakos, A., Katsanos, S., Papanikitas, K. and Patsilinakos, S. (2011) Rapid Desensitisation of Patients with Aspirin Allergy Who Undergo Coronary Angioplasty. Hellenic Journal of Cardiology, 52, 307-310.

[35] Messaad, D., Sahla, H., Benahmed, S., Godard, P., Bousquet, J. and Demoly, P. (2004) Drug Provocation Tests in Patients with a History Suggesting an Immediate Drug Hypersensitivity Reaction. Annals of Internal Medicine, 140, 10011006. http://dx.doi.org/10.7326/0003-4819-140-12-200406150-00009

[36] Kowalski, M.L., Makowska, J.S., Blanca, M., et al. (2011) Hypersensitivity to Nonsteroidal Anti-Inflammatory Drugs (NSAIDs) - Classification, Diagnosis and Management: Review of the EAACI/ENDA and GA2LEN/HANNA. Allergy, 66, 818-829. http://dx.doi.org/10.1111/j.1398-9995.2011.02557.x

[37] Thong, B.Y. (2011) Clinical Applications of Drug Desensitization in the Asia-Pacific Region. Asia Pacific Allergy, 1, 2-11. http://dx.doi.org/10.5415/apallergy.2011.1.1.2

[38] Cardona, R., Ramírez, R.H., Reina, Z., Escobar, M.F. and Morales, E. (2009) Alergia e intolerancia a antiinflamatorios no esteroides: Desensibilización exitosa en tres casos y revisión de la literatura. Biomédica, 29, 181-190.

[39] Woo, H.Y., Kim, Y.S., Kang, N.I., Chung, W.C., Song, C.H., Choi, I.W., Choi, I.H. and Lee, H.K. (2006) Mechanism for Acute Oral Desensitization to Antibiotics. Allergy, 61, 954-958. http://dx.doi.org/10.1111/j.1398-9995.2006.01147.x

[40] Odom, S., Gomez, G., Kovarova, M., Furumoto, Y., Ryan, J.J., Wright, H.V., Gonzalez-Espinosa, C., Hibbs, M.L., Harder, K.W. and Rivera, J. (2004) Negative Regulation of Immunoglobulin E-Dependent Allergic Responses by Lyn kinase. Journal of Experimental Medicine, 199, 1491-1502. http://dx.doi.org/10.1084/jem.20040382

[41] Malaviya, R. and Uckun, F.M. (2002) Role of STAT6 in IgE Receptor/FcepsilonRI-Mediated Late Phase Allergic Responses of Mast Cells. Journal of Immunology, 168, 421-426.

[42] Morales, A.R., Shah, N. and Castells, M. (2005) Antigen-IgE Desensitization in Signal Transducer and Activator of Transcription 6-Deficient Mast Cells by Suboptimal Doses of Antigen. Annals of Allergy, Asthma \& Immunology, 94, 575-580. http://dx.doi.org/10.1016/S1081-1206(10)61136-2

[43] Strobel, S. and Mowat, A.M. (2006) Oral Tolerance and Allergic Responses to Food Proteins. Current Opinion in Allergy \& Clinical Immunology, 6, 207-213. http://dx.doi.org/10.1097/01.all.0000225162.98391.81

[44] Mucida, D., Kutchukhidze, N., Erazo, A., Russo, M., Lafaille, J.J. and Curotto de Lafaille, M.A. (2005) Oral Tolerance in the Absence of Naturally Occurring Tregs. Journal of Clinical Investigation, 115, 1923-1933. http://dx.doi.org/10.1172/JCI24487

[45] van Wijk, F., Wehrens, E.J.M., Nierkens, S., Boon, L., Kasran, A., Pieters, R. and Knippels, L.M.J. (2007) CD4 ${ }^{+}$CD25 ${ }^{+}$T Cells Regulate the Intensity of Hypersensitivity Responses to Peanut but Are Not Decisive in the Induction of Oral Sensitization. Clinical \& Experimental Allergy, 37, 572-581. http://dx.doi.org/10.1111/j.1365-2222.2007.02681.x

[46] Martorell Aragones, A., Felix Toledo, R., Cerda Mir, J.C. and Martorell Calatayud, A. (2007) Oral Rush Desensitization to Cow Milk. Following of Desensitized Patients during Three Years. Allergologia et Immunopathologia, 35, 174-176. http://dx.doi.org/10.1157/13110311

[47] Staden, U., Blumchen, K., Blankenstein, N., Dannenberg, N., Ulbricht, H., Dobberstein, K., Ziegert, M., Niggemann, B., Wahn, U. and Beyer, K. (2008) Rush Oral Immunotherapy in Children with Persistent Cow’s Milk Allergy. Journal of Allergy and Clinical Immunology, 122, 418-419. http://dx.doi.org/10.1016/j.jaci.2008.06.002

[48] Meglio, P., Bartone, E., Plantamura, M., Arabito, E. and Giampietro, P.G. (2004) A Protocol for Oral Desensitization in Children with IgE-Mediated Cow’s Milk Allergy. Allergy, 59, 980-987. 
http://dx.doi.org/10.1111/j.1398-9995.2004.00542.x

[49] Szczeklik, A. and Stevenson, D.D. (1999) Aspirin-Induced Asthma: Advances in Pathogenesis and Management. Journal of Allergy and Clinical Immunology, 104, 5-13. http://dx.doi.org/10.1016/S0091-6749(99)70106-5

[50] Rossini, R., Angiolillo, D.J., Musumeci, G., Scuri, P., Invernizzi, P., Bass, T.A., Mihalcsik, L. and Gavazzi, A. (2008) Aspirin Desensitization in Patients Undergoing Percutaneous Coronary Interventions with Stent Implantation. American Journal of Cardiology, 101, 786-789. http://dx.doi.org/10.1016/j.amjcard.2007.10.045

[51] Warrington, R. and Silviu-Dan, F. (2011) Drug Allergy. Allergy, Asthma \& Clinical Immunology, 7, S10. 